\title{
Resistir a Hegel. Apuntes para una lectura heideggeriana de la consumación de la metafísica
}

\author{
Resisting Hegel. \\ Notes for a Heideggerian reading of \\ the attainment of metaphysics
}

\author{
HERNÁN J. CANDILORO \\ CONICET - UBA (Argentina)
}

Recibido: 01/06/2012 Aceptado:04/04/2013

\section{RESUMEN}

Heidegger se ha sentido fuertemente interpelado por la obra de Hegel. Tal es así que ésta recorre espectralmente su proyecto de una Destruktion de la historia de la metafísica. Hegel es, en este sentido, uno de sus interlocutores privilegiados en el diálogo emprendido con la tradición. El presente trabajo se propondrá, en este contexto, intentar elucidar este vínculo entre los pensamientos heideggeriano y hegeliano, a partir de lo que postularemos como la necesidad de ejercer una resistencia a la metafísica y de abrir la posibilidad de un «reconocimiento de la diferencia».

\section{PALABRAS CLAVE}

HEIDEGGER, HEGEL, DECONSTRUCCIÓN, (IN)ACABAMIENTO, DIALÉCTICA

\section{ABSTRACT}

Heidegger felt himself questioned by Hegel's work. Indeed, the latter crosses spectrally his project of a Destruktion of the history of metaphysics. Hegel is, in that sense, one of his privileged interlocutors in the dialog with tradition. This paper proposes to clarify the link between Heideggerian and Hegelian thoughts, from what we will postulate as the necessity to resist metaphysics and to open the possibility of «recognition of the difference».

KEY WORDS

HEIDEGGER, HEGEL, DECONSTRUCTION, (IN)COMPLETION, DIALECTICS

\footnotetext{
(C) Contrastes. Revista Internacional de Filosofía, vol. XIX-No 1 (2014), pp. 7-26. ISSN: 1136-4076

Departamento de Filosofía, Universidad de Málaga, Facultad de Filosofía y Letras Campus de Teatinos, E-29071 Málaga (España)
} 
«La superación de Hegel es el paso necesario que se ha de dar en el desarrollo de la filosofía occidental si ésta ha de permanecer todavía viva.» Martin Heidegger, Los problemas fundamentales de la fenomenología. ${ }^{1}$

«Pues, de este texto [La fenomenología del espíritu de Hegel], J. Hyppolite ha buscado y recorrido todas las salidas, como si su inquietud fuese: ¿se puede todavía filosofar allí donde Hegel ya no es posible?; ¿puede existir todavía una filosofía que ya no sea hegeliana?; ¿aquello que no es hegeliano en nuestro pensamiento es necesariamente no filosófico?; ¿y aquello que es antifilosófico es forzosamente no hegeliano?» Michel Foucault, El orden del discurso. ${ }^{2}$

\section{INTRODUCCIÓN}

TODAS LAS FORMAS DE RESISTENCIA comparten la necesidad de un reconocimiento, puesto que sólo a través de éste se hace manifiesto el horizonte común sobre el que tiene lugar cualquier enfrentamiento. Sea ya el reconocimiento del campo de batalla, el territorio compartido sobre el que se lleva a cabo una disputa, o el reconocimiento del adversario en su carácter hostil, su poder e intensidad y, por sobre todo, su altura y relevancia; toda resistencia parece entonces debatirse sobre un trasfondo compartido sin el cual ninguna oposición efectiva puede tener lugar. Así pues, la resistencia sólo puede ser medida y considerada en el contexto de este horizonte del reconocimiento que hace posible la coincidencia confrontativa - el choque - de los opuestos. La resistencia no es entonces un cuestionamiento externo, la toma de la posición ajena con el consecuente desplazamiento del otro. Por el contrario, para ser tal la resistencia debe producirse desde dentro, a partir de un espacio común y compartido y al interior del cual una posición rehúsa ser reducida por la posición contraria.

Resistir es así oponer resistencia a un otro que, en mayor o menor medida, participa de lo propio y al cual, por lo tanto, es posible reconocer en tanto que adversario contra el cual se lucha. Éste debe ser a su vez depositario de una cierta admiración, puesto que es en el reconocimiento de la dignidad del oponente donde se mide el valor y la fortaleza de la propia resistencia a su influjo. Pero resistir es también oponer resistencia a la tentación de suscribir acríticamente la posición del otro, perdiendo el lugar propio y resignando el enfrentamiento. La resistencia es, en este sentido, la condición de una hermenéutica auténtica,

1 Tr. J. J. García Norro. Madrid: Trotta, 2000, p. 222.

2 Tr. A. González Troyano. Buenos Aires: Tusquets, 1992, p. 60. 
que pregunte y se pregunte por el sentido del texto, evitando la repetición de frases hechas que la prive de su decir propio.

La resistencia es, en suma, lo que se opone en el marco de un horizonte común que se considera prestablecido. Y sin embargo es necesario que nos preguntemos: ¿no es posible también oponer resistencia a ese horizonte mismo, evitando darlo por sentado para de esa manera lograr comprenderlo críticamente? ¿Y no es acaso necesario resistir a ese horizonte cuando se trata de un cuestionamiento radical, que por cierto marca la tónica de una gran parte de la filosofía por lo menos desde Descartes hasta nuestros días? Se trataría entonces de poner en cuestión los presupuestos de toda resistencia o, lo que es lo mismo, de explicitar la posibilidad de una resistencia más profunda a la simple oposición, a saber: la crítica de los fundamentos sobre los que se sostiene el propio pensar. Se trataría, dicho sencillamente, de abrir esa instancia en la que el pensamiento logra ponerse en cuestión a sí mismo de un modo radical y a partir de la cual puede también reconocerse en su capacidad crítica. ¿Pero desde qué otro trasfondo ulterior será posible oponer resistencia al horizonte común que permite el reconocimiento entre opuestos? Para ello será menester sumergirse en el horizonte del reconocimiento para poder vislumbrar en él un horizonte ulterior de la diferencia.

$\mathrm{Si}$, como dijimos anteriormente, no hay resistencia sin reconocimiento, es necesario entonces señalar que tampoco hay reconocimiento sin resistencia. Así pues, todo reconocimiento implica una instancia de alteridad que rehúsa ser reducida y en cuya diferencia hace posible el reconocimiento en tanto tal. De esta manera, debe quedar en claro que la resistencia al horizonte del reconocimiento no equivale a un sencillo «romper amarras» con aquello a lo que se resiste, sino más bien todo lo contrario: resistir al fundamento sobre el que se sostiene el propio pensar es la condición de posibilidad para confluir críticamente con él, haciendo de la diferencia el horizonte común que reúne a los opuestos en su oposición.

Los adversarios comparten entonces su oposición misma, y de esa manera se encuentran impedidos de toda identificación que resuelva el conflicto y anule el reconocimiento. Los opuestos se encuentran reunidos en su diferenciación recíproca, dando lugar a un nuevo concepto de reconocimiento que se presenta imposibilitado de una síntesis última: el reconocimiento de la diferencia. Como veremos a continuación, la meta de la lectura heideggeriana de Hegel puede ser enmarcada en ese intento de ejercer una resistencia a dicho horizonte del reconocimiento que, entendido como el horizonte común a la tradición, ha recibido el nombre de «metafísica».

Resistir al horizonte del reconocimiento mediante la explicitación de un horizonte ulterior de la diferencia significa, por ende, resistir también a la comprensión del ser a partir de un absoluto o fundamento último. Como desa- 
rrollaremos más adelante, esta resistencia no es sino un intento por deconstruir la historia de la metafísica, o mejor, la posibilidad de su explicitación en la forma de una totalidad concluida.

En el marco de esta relación entre los pensamientos hegeliano y heideggeriano, el presente trabajo se propone indagar en algunos aspectos que vinculan conflictiva, pero también complementariamente ambas filosofías. En este sentido, el presente trabajo se propone como preludio a una reinterpretación de la filosofía de Hegel a partir de la crítica heideggeriana.

\section{RESISTIR A LA DIALÉCTICA}

Sin lugar a dudas, Hegel constituye una de las figuras destacadas de la historia de la filosofía. Por su influjo en el pensamiento posterior y también anterior, al proponer una relectura de la historia de la filosofía en clave dialéctica y por sus consecuencias en todo nivel del conocimiento. Pero quizá su mayor importancia se manifieste especialmente en las resistencias que su pensamiento ha generado. Si bien una lectura un tanto ingenua pareciera sugerir que la intensidad con la que se lo lee ha decrecido con la supuesta superación del marxismo, no obstante es necesario prestar atención al hecho de que una gran parte del pensamiento que cobra relieve en la segunda mitad del siglo XX se erige como una peculiar resistencia al poder totalizador de su filosofía. Pero una resistencia que -y he aquí su peculiaridad-implica la paradoja de no dejarse reducir dialécticamente.

Una gran porción de la filosofía contemporánea hasta nuestros días puede ser así leída en clave hegeliana en términos de resistencia: resistencia al sistema de Hegel, pero en especial a la dialéctica hegeliana a través de la cual la tradición metafísica llega a su consumación. Así pues, la resistencia contemporánea a la dialéctica hegeliana, entendida esta última como la efectivización del acabamiento de la metafísica -y deberemos ver con mayor detalle en qué sentido puede ser así entendida-, se corresponde con la iniciativa de sustraerse al pensamiento metafísico que no ha dejado aún de resonar en la obra de sucesivos pensadores post-heideggerianos. ${ }^{3}$

Como veremos más adelante, resistir al sistema hegeliano y en especial a su dialéctica significa resistir a la metafísica misma. Ahora bien, ¿cómo pensar una resistencia a la dialéctica que no termine siendo devorada por su poder especulativo? ¿Y cómo pensar una resistencia que no se deje incluir en el esquema binario - y dialéctico - en el que tiene lugar la historia tradicional

3 Nos referimos especialmente a lo que podríamos caracterizar como una «filosofía de la alteridad» de fuerte raigambre francesa e italiana, en la que se destacan autores como Jacques Derrida, Jean-Luc Nancy, Giorgio Agamben y Emmanuel Lévinas entre muchos otros cuya obra, a nuestro entender, presenta una fuerte impronta del pensamiento de Martin Heidegger. 
de la filosofía? Estas preguntas señalan en dirección a la posibilidad de una resistencia radical, es decir, de una resistencia sostenida sobre el fundamento de la diferencia. Se trata así, por paradójico que pueda sonar, de resistir a la dialéctica misma por la cual, a decir del propio Hegel, la propia estructura binaria en la que consiste la metafísica llega a su consumación y muestra su verdad.

El pensamiento de Heidegger constituye uno de los epicentros donde arraiga gran parte de la resistencia contemporánea al sistema de Hegel. En este sentido, el vínculo que une a Heidegger con Hegel puede ser analizado en dos planos distintos: por un lado, a partir de las numerosas referencias directas a la filosofía de Hegel que aparecen bajo la forma de comentarios, notas a pie de página, referencias bibliográficas, o bien directamente como discursos o seminarios dedicados íntegramente a la interpretación textual de la obra hegeliana; ${ }^{4}$ pero por otro lado, debemos también prestar atención al hecho de que, en tanto que diálogo crítico con la historia de la metafísica, gran parte -si no toda la obra de Heidegger-puede ser tomada a su vez como un diálogo con el sistema de Hegel en particular. Por consiguiente, la relación crítica entre ambos filósofos debe ser considerada en estos dos niveles: primero, a partir de las referencias directas de Heidegger hacia Hegel; y segundo, a la manera de un diálogo crítico, velado e indirecto que tiene lugar en el marco de la así llamada historia de la metafísica.

Ya sea directa o indirectamente, que se discuta con Hegel o con la historia de la metafísica en general, el espectro hegeliano ronda inexorablemente la obra heideggeriana. ${ }^{5}$ En efecto, tanto Hegel como Nietzsche y Schelling son propuestos por Heidegger como las encarnaciones más destacadas de la historia de la metafísica y, en ese sentido, como los interlocutores predilectos con los que debe medirse todo intento por desmontar esta última ${ }^{6}$. Tres interlocutores

4 Podemos mencionar como significativos los tomos GA68 - que contiene una confrontación con Hegel a través del problema de la negatividad y también una «Dilucidación de la «Introducción» a la Fenomenología del espíritu»-, GA32 - Hegels Phänomenologie des Geistes-, el texto «El concepto de experiencia de Hegel» contenido en GA5 - Holzwege-, la conferencia «Hegel y los griegos» que aparece en GA9 - Wegmarken -, la conferencia «La constitución onto-teo-lógica de la metafísica» que forma parte de GA11, pero también la sección VI, §§ 78-83 sobre la temporalidad, de Ser y tiempo. Como puede verse, la reflexión sobre Hegel constituye una gran parte de la obra heideggeriana.

5 «Tan innegable es que la sombra de Hegel acompañó obsesivamente todo el camino del pensar de Heidegger como el hecho de que éste se limita - muy sospechosamente - a citar la Fenomenología (hasta el cap. IV), los prólogos, introducciones y final de la Lógica y la introducción a la Enciclopedia (para no hablar de préstamos de citas — por ejemplo de la Filosofía de la naturaleza de Jena — por parte de estudiantes)». F. Duque, «Con Hegel y Heidegger: Amenaza de la finitud», Anales del Seminario de Metafisica, 24 (1990), p. 11.

$6 \mathrm{Al}$ respecto cf. D. O. Dahlstrom, «Heidegger and German Idealism», en H. Dreyfus y M. Wrathall (eds.), A companion to Heidegger. Oxford: Blackwell, 2005, pp. 65-79. 
que comparten con Heidegger un mismo pensamiento fundamental, aunque a decir de éste no hayan podido sino reducirlo a su interpretación metafísica. ${ }^{7}$ Hegel, Nietzsche y Schelling han tenido la fortaleza de resistir al imperar de lo ente al pensar el fundamento abismal -y diferencial- sobre el que aquél se presenta, aunque hayan luego tenido que ceder, asimilándolo a la metafísica. No ha sido otra cosa que la posibilidad de esa resistencia, vislumbrada en sus pensamientos, la que, para Heidegger, ha hecho de ellos «grandes pensadores».

Ahora bien, es importante prestar atención a una cuestión muchas veces pasada por alto, y que no obstante resulta fundamental para poder comprender el proyecto heideggeriano desde su raíz. Debemos atender a que el hecho de que Hegel represente la consumación de la historia de la metafísica no significa en lo más mínimo una valoración negativa de parte de Heidegger, conclusión que una lectura apresurada parece sugerir cuando cree ver cierto carácter peyorativo con el que éste calificaría a la metafísica. Sin embargo, no sólo éste no es el caso, sino que más bien sucede todo lo contrario: la metafísica es el horizonte de comprensión en el que nos encontramos, donde hemos sido arrojados, con el que tratamos cotidianamente y que se trata de comprender desde su origen; aunque ello implique tener que ejercer cierta violencia sobre él al intentar explicitar su fundamento obturado. En efecto, la metafísica se sostiene sobre la obturación de su origen, la metafísica es ella misma dicha obturación por la cual, postulando un fundamento absoluto, conduce a la anulación de toda resistencia. Cuestionar la metafísica significa entonces referirse críticamente al modo cotidiano de dirigirse hacia lo que nos rodea y, por ende, poner también en cuestión la interpretación habitual que tenemos de nosotros mismos, frente a una cotidianidad que tiende a evitar toda conmoción y crítica.

Pero como mencionamos antes, Hegel es para Heidegger un «gran pensador», lo que lo ubica no sólo ya en línea con Nietzsche y Schelling, sino también con los primeros pensadores occidentales, Heráclito y Parménides. ${ }^{8}$ Hegel no es entonces el responsable de la radicalización de una comprensión errónea del ser en la que consistiría la metafísica, sino, en cambio, aquel pensador que, llevando la metafísica hasta su límite a partir de lo que ésta tiene de propio, ha sabido descender hasta el fundamento más profundo del pensar. Hegel es, en suma, un pensador del ser, un pensador fundamental, esto es, un pensador del origen de la metafísica. Por consiguiente, el asunto [Sache] del pensar he-

7 Resulta interesante señalar que quien sí ha podido expresar la diferencia en su diferenciación ha sido un contemporáneo - y amigo - de Hegel: Hölderlin. Cf. M. Heidegger, « ¿Y para qué poetas?», Caminos de bosque, tr. H. Cortés y A. Leyte. Madrid: Alianza, 2005, pp. 199-238.

8 No obstante, es interesante destacar que, como señala Félix Duque «Sólo Parménides (aunque no con tanta intensidad y asiduidad) goza con Hegel del privilegio de estar al inicio - 5/ [19]16 y al final—12/1973 — de su itinerario intelectual». F. Duque, loc. cit., p. 13. 
geliano coincide con el asunto de la filosofía misma ${ }^{9}$-incluso si es entendida como metafísica - y por lo tanto con el de los otros grandes pensadores. Sin embargo, y pese a haber descendido hacia el abismo del fundamento, no ha podido sino reducirlo al ente, volviéndolo a capturar en la estructura misma de la metafísica, en lugar de sacarlo a relucir en su diferenciación propia. Hegel ha entonces vislumbrado el abismo, pero lo ha vuelto a incorporar a la metafísica, que resulta así fortalecida.

Como expresión máxima de la metafísica, Hegel ha pensado aquello que, en tanto que asunto del pensar, debía ser pensado, pero no ha sabido mantenerlo en su carácter abismal originario. No obstante, el grado de radicalidad con el que Hegel obtura el abismo poniendo en su lugar una ousía absoluta, debe ser tomado como un signo que, correlativamente, nos indica la profundidad insondable con la que ha pensado el ser. Así pues -de acuerdo a Heidegger-su elevación hacia el absoluto se sostendría sobre un descenso anterior al abismo de la diferenciación originaria.

Hegel ha sabido descender hasta el fundamento del pensar, desde el cual ha emprendido el ascenso hasta el Espíritu absoluto y esto hace de él -junto con Nietzsche, Schelling y, no podemos obviar, Heidegger mismo- lo que este último denomina un «gran pensador». En tanto el sistema hegeliano encarna a través de la dialéctica el máximo desarrollo de la metafísica, Hegel ha sido también quien ha descendido con mayor profundidad hasta el fundamento del pensar. Por consiguiente, si Hegel es el pensador que ha conducido la metafísica hasta sus últimas consecuencias, al mismo tiempo es también quien ha puesto los cimientos más firmes para su posible deconstrucción, los que no obstante se encontrarían presupuestos, ocultos e impensados en su obra, y que se trataría de desenterrar.

Hegel ha pensado metafísicamente la esencia y verdad de la metafísica; he allí su propia limitación. Sin embargo, en el seno de esta recursividad se abre un intervalo sobre el cual será necesario poner el acento, con la intención de hacer patente el punto de fuga sin el cual la metafísica es ciega a su propio influjo. Ello nos permitirá comprender, por una parte, el proyecto deconstructivo de Heidegger, pero por otra, las implicancias y el valor de la historia de la metafísica consumada en la filosofía de Hegel. Por lo tanto, será menester

9 «Esto quiere decir, si lo nombramos con una denominación concisa aunque difícil de pensar de modo conforme a su asunto, que para Hegel el asunto del pensar es «el pensamiento», el cual, desarrollado hasta la máxima libertad de su esencia, es «la idea absoluta». Hegel dice de ella, hacia el final de la Ciencia de la lógica (ed. Lass, tomo II, 484): «sólo la idea absoluta es ser, vida imperecedera, verdad que se sabe a sí misma, y toda verdad». Con ello, Hegel mismo le da expresamente al asunto de su pensar ese nombre que está por encima de todo el asunto del pensar occidental: el nombre ser». M. Heidegger, «La constitución onto-teo-lógica de la metafísica», tr. H. Cortés y A. Leyte, Identidad y diferencia. Barcelona: Anthropos, 1990, p. 111. 
confrontar a este último para hacer patente lo que ha pensado, y no obstante ha tenido que sepultar bajo el imperio del absoluto, para de esa manera lograr una comprensión de la historia de la metafísica en su conjunto. Será necesario entonces emprender el descenso hasta el fundamento del pensar que emparenta a Hegel con los otros grandes pensadores de la historia de la filosofía, y donde Heidegger considera que residiría el único asunto de la filosofía en tanto tal.

\section{Hegel: PENSADOR DEL (IN)ACABAMIENTO DE LA METAFísiCA}

Heidegger suele desestimar el recurso a la biografía como metodología filosófica. Para él el nombre de un pensador nombra el asunto de su pensar, y aunque lo haya hecho desde una perspectiva metafísica, Hegel ha pensado la esencia de la metafísica, el ser en su profundidad insondable. Hegel es, en este sentido, el nombre de la metafísica absolutamente desplegada, puesto que ha sabido explicitar en su totalidad, conduciendo a la verdad, el abismo del ser. Y sin embargo, ¿en qué sentido puede hablarse de una «explicitación total» del ser? ¿Es acaso el ser algo que pueda ser explicitado sin resistencias? ¿Algo que esté ahí, yaciente, simplemente esperando la metodología adecuada -que en este caso sería la dialéctica hegeliana- para ser desocultado en su totalidad? ¿Y no podría el ser, en cambio, consistir en la resistencia misma a la explicitación? Como veremos a continuación, entre lo pasible de ser explicitado y aquello que resiste a ser puesto bajo la luz de lo presente se debate la diferencia entre ser y ente, la «diferencia ontológica» que es borrada por la metafísica. ¿Pero qué es para Heidegger esa metafísica que Hegel conduciría a su verdad? ¿Y qué significa aquí «verdad»? Será necesario que avancemos lentamente sobre estas preguntas.

«Metafísica» es, para Heidegger, un nombre propio. Con él se nombra una peculiar tradición interpretativa por la cual lo que aparece es comprendido, en su vertiente positiva, como un ente y, por la negativa, a partir del olvido del ocultamiento en que consistiría el ser. «Olvido del ocultamiento del ser», debemos reparar en los matices de esta frase. $\mathrm{Si}$-como sostiene Heidegger-el ser es esencialmente ocultamiento y resistencia, entonces no puede ser sencillamente puesto a la luz y explicitado sin que su mostración lo desfigure; lo que ciertamente sucede cuando se lo comprende a la manera de un ente. Por consiguiente, el ser requiere ser mostrado en su ocultamiento mismo, es decir, en tanto aquello que no puede, que rehúsa y resiste ser explicitado como un ente «ante los ojos».

Puesto que no es un ente, el ser es lo que resiste a la explicitación. Por lo tanto la consumación hegeliana de la metafísica, entendida como la explicitación absoluta del ente, no puede sino redundar en un mayor ocultamiento del ser y por ende en una potenciación de la resistencia en la que éste consiste. 
Olvidando el ocultamiento en que consiste el ser, la metafísica se caracterizaría entonces por mantener impensada la diferencia ontológica entre el ser y el ente. En este punto se torna necesario señalar que, de la misma manera que sucede con la crítica que Heidegger le destina a la metafísica -y que atraviesa de cabo a rabo la obra heideggeriana-, la discusión con Hegel no se propone señalar o corregir errores o desatinos. Por el contrario, la deconstrucción persigue una comprensión profunda del sentido de ambos - ser y ente- a partir de la elucidación de su fundamento impensado. Y este fundamento ha sido impensado, puesto que no ha sido presentado en su diferenciación originaria y resistencia a lo ente, sino que ha sido considerado a partir de su aspecto metafísico de permanencia en el presente, escondiendo su diferencia con la metafísica misma y toda posibilidad de resistencia a ésta.

Volver a señalar la diferencia ontológica, desenterrándola del olvido al que la ha confinado la metafísica, equivale entonces a comprender a esta última desde su origen. La diferencia ontológica - entendida como el punto de contacto y distinción entre el ser y el ente- constituiría así el origen de la metafísica, pero también -es necesario decirlo- la posibilidad de otro pensamiento. Un otro pensamiento de la metafísica -donde el genitivo debe ser comprendido en su valor objetivo y subjetivo-, es decir, otro pensamiento que piensa la metafísica en su diferencia originaria, pero también otra manera de pensar desde una metafísica que ha logrado comprenderse en su lugar propio y asumiendo sus límites. Ciertamente, comprender cabalmente la metafísica significa reconocer sus límites, y por ende tener también una comprensión de aquello que se extiende más allá de ellos, puesto que es en los límites donde tiene lugar su origen diferencial ${ }^{10}$.

Pero como ya hemos mencionado, Hegel ha pensado la esencia de la metafísica, aunque lo haya hecho desde y para la metafísica misma y por lo tanto no haya podido expresarla en su diferenciación originaria, teniendo que dejarla como impensada. Hegel ha pensado la esencia de la metafísica desde su acabamiento absoluto, pero no ha sacado de su olvido al ocultamiento del ser, puesto que se ha movido sobre una comprensión de la explicitación en términos de presencia «ante los ojos». Explicitar es, en este sentido, llevar a la luz y mostrar en su verdad, donde esta última es entendida en términos de «adecuación»y «certeza» absoluta ${ }^{11}$.

10 En este punto el proyecto heideggeriano se cruza con el de la Crítica de la razón pura: no ya delimitar el horizonte de una metafísica posible, sino ahora delimitar a la metafísica misma en relación a un horizonte mayor de lo posible.

11 «Verdad es para Hegel la absoluta certeza del sujeto absoluto que se sabe a sí mismo. » M. Heidegger, «Hegel y los griegos», tr. H. Cortés y A. Leyte, Hitos. Madrid: Alianza, 2007, p. 354 . 
Debemos entonces preguntarnos: ¿cómo podría mostrarse explícitamente la diferencia con la metafísica, si la explicitación misma es pensada como el poner «ante los ojos», «en persona» o «en carne y hueso»? ¿Cómo puede entonces explicitarse la diferencia con la metafísica, cuando la explicitación es comprendida como consumación, despliegue y puesta en acto de la metafísica misma? Frente a ello, la peculiar explicitación que requiere el ser deberá sostenerse sobre una comprensión distinta de la verdad, que Heidegger rastreará en el mundo griego. Será entonces retomando el sentido de la verdad como a-létheia, des-ocultamiento [Ent-bergung], que no sólo podrá comprenderse la verdad entendida como «certeza», sino que además se abrirá la comprensión de aquello que resiste a la metafísica y de donde, sin embargo, proviene su sentido. Se trata entonces de encontrar «la verdad de la metafísica», pero donde ésta ya no será entendida metafísicamente como permanencia de lo presente, sino a partir de una concepción ampliada por la alétheia griega. ${ }^{12}$

Hegel es entonces el «gran pensador» de la metafísica. En su olvido del ser ha totalizado la historia en la forma de la presencia absoluta, y por consiguiente ha derribado toda posibilidad de resistencia dentro de la metafísica. En efecto, la dialéctica tiene la capacidad de incorporar y sintetizar las resistencias. Sin embargo, al presuponer una comprensión de la verdad sostenida sobre la presencia «ante los ojos» -y por lo tanto sobre la comprensión del ser como un ente y el olvido del ser-, la dialéctica sólo alcanza a desplegar la metafísica, y se encuentra impedida de explicitar el ser. Para que esto último pueda ser realizado es necesario otro concepto de verdad y, por ende, es menester también ir más profundo hasta desmontar la comprensión metafísica de lo que se da. Con esta intención, Heidegger retomará el concepto griego de verdad, para hacer patente la posibilidad de una explicitación de otro orden, que tenga la capacidad de mostrar en sí mismo, es decir, sin deformarlo, aquello que rehúsa ser reducido a lo ente. ${ }^{13}$

En este sentido, si a través de la explicitación del absoluto Hegel ha simultáneamente radicalizado la posibilidad de una resistencia a la metafísica, también es verdad que la ha dejado en el olvido. Ha preparado el terreno, sin avanzar en el desarrollo de este otro pensar de la diferencia. Para ello será necesario ampliar el concepto metafísico de verdad para de ese modo posibilitar una explicitación de los límites y resistencias a la metafísica.

12 Cf. M. Heidegger, «De la esencia de la verdad», tr. H. Cortés y A. Leyte, Hitos. Madrid: Alianza, 2007, pp. 151-171.

13 En este sentido, debemos señalar que el gran aporte heideggeriano en lo que refiere a esta posibilidad de explicitar el ser consiste en su redefinición del concepto de «fenómeno» presentada en el $\$ 7$ de Ser y tiempo y que recibe el nombre de «concepto fenomenológico de fenómeno». Cf. M. Heidegger, El ser y el tiempo, tr. J. Gaos. Buenos Aires: FCE, 2009, pp. 37-49. 


\section{HACIA UNA RECONSTRUCCIÓN DE LA METAFÍSICA}

Hegel ha pensado metafísicamente la verdad de la metafísica, y no a partir de su diferencia intrínseca. Pero el hecho de que Heidegger se proponga la explicitación del fundamento impensado por y de la metafísica, no equivale a la realización de algo que ésta haya sencillamente pasado por alto. Por el contrario, en tanto que lo que se trata de pensar es la diferencia con la metafísica misma, en la que no obstante reside su fundamento, esta última no puede ser pensada desde sí, sin atender a su esencial inadecuación consigo misma. Deconstruir la metafísica significa entonces señalar el carácter oscilante entre ésta y su esencia, por el cual el origen de la metafísica resiste ser mostrado metafísicamente. En efecto, y como ya lo mencionamos anteriormente, la metafísica es la obturación misma de su fundamento abismal y, por lo tanto, este último no puede ser explicitado en términos que no sean los de una resistencia respecto de aquella. Esta explicitación -a la que Heidegger denomina Destruktion y que, no sin variaciones importantes, dará lugar a la «deconstrucción» postulada por Derrida ${ }^{14}$ - puede entonces ser equiparada a una «implosión de la metafísica» desde su fundamento. Pero una implosión que, como veremos, en lugar de «liquidar» la metafísica -tal y como sostienen Ferry y Renaut, haciendo referencia al sujeto- la reconstruye. ${ }^{15}$

En tanto que explicitación del fundamento de la metafísica, la Destruktion heideggeriana implica la afirmación del origen de la historia de la metafísica, la «repetición de lo inicial» a partir de lo cual aquella surge en el tiempo. Sin embargo, esta repetición no significa en absoluto una monotonía del darse otra vez lo mismo. Por el contrario, a diferencia de la metafísica la repetición deconstructiva afirma el origen de esta última dejándolo imperar como lo que es, en lugar de hacerlo a través de la obturación desfiguradora. Afirmando el

14 Si bien se ha establecido la traducción de Destruktion por «deconstrucción», sería necesario -aunque exceda el marco del presente trabajo- reparar en la crítica derridiana de lo originario, de modo tal que pueda evaluarse si su postulación de la deconstrucción no constituye una crítica irreconciliable con la estrategia deconstructiva de Heidegger.

15 Ferry, L y Renaut, A., La penseé 68, Gallimard, Paris, 1988, pp. 69, 76, 89, 121, 123, 140. Cf. también F. Duque, «Martin Heidegger : En los confines de la metafísica », Anales del Seminario de Historia de la Filosofia, 13 (1996), p. 24 : « En cambio, la pregunta por el ser: por su sentido, verdad y localización (las tres estaciones del sendero seguido por Heidegger), no sería ya una pregunta metafísica, sino que «desmantelaría», pondría al descubierto sus cimientos. No para establecer otros más sólidos, ni para superar a la metafísica, sino para reponerse de ésta, para remontarla (los dos sentidos del alemán Verwindung, tal como se dice p.e. que alguien se «repone» de una enfermedad; es más: habría que entender ese «remonte» no como una «curación», sino como una lúcida conciencia de la inevitabilidad de esa enfermedad, vista ahora como un «síntoma», en un sentido parecido al de la «abducción» freudiana)». 
origen de la metafísica pero de otra manera, la repetición es más bien una iteración, ${ }^{16}$ esto es, una repetición transfiguradora de lo mismo.

Nos encontramos entonces con una torsión entre la esencia de la metafísica y la metafísica misma. Ciertamente, si por una parte la metafísica muestra desfiguradamente su origen, por otra parte una mostración auténtica de este último no puede sino derivar en una transfiguración de lo ente que, sobre el trasfondo del ser, aparece con una vivacidad renovada.

Pensada metafísicamente, la esencia de la metafísica ha permanecido impensada en el pensamiento de Hegel, lo que quiere decir que habita su pensamiento aunque no pueda hacerlo explícitamente como tal, es decir, en su diferenciación intrínseca; en razón de los límites del concepto metafísico de verdad antes señalados. Esa imposibilidad para que la esencia de la metafísica habite explícitamente la obra de Hegel es justamente la que determina el carácter metafísico de ésta. Así pues, la única manera de hacer explícita la esencia de la metafísica reposa en mostrarla en su resistencia a ser explicitada metafísicamente. Se trata pues de hacer evidente lo que se oculta en la consumación de la metafísica llevada a cabo por Hegel, esto es, de indicar aquello que se esconde con mayor intensidad en la máxima explicitación. Ahora bien, y queremos insistir con esto, si, como consumación de la metafísica, el sistema hegeliano puede esconder en su grado máximo la esencia de la metafísica, esto es porque ha sido el propio Hegel el que se ha sumergido hasta lo más profundo del abismo del ser. ${ }^{17}$

En suma, la discusión emprendida por Heidegger no será tanto contra Hegel, sino más bien con Hegel, y frente a aquellas interpretaciones que no llegan hasta el fondo de lo pensado por este autor. ${ }^{18} \mathrm{El}$ intento consistirá en hacer explícito aquello que Hegel no pudo explicitar desde la metafísica, aunque haya sido -y en esto Heidegger no deja lugar a dudas- quien más se ha acercado a

16 Cf. J. Derrida, «Firma, acontecimiento, contexto», tr. C. González Marín, Márgenes de la filosofía. Madrid: Cátedra, 1998, pp. 347-372.

17 «Un fenómeno puede además estar enterrado. Esto implica: estaba ya descubierto, pero volvió a quedar encubierto. Este encubrimiento puede llegar a ser total, o bien, y es la regla, lo ya descubierto es aún visible, pero sólo en la forma del «parecer ser...». Mas, cuanto de «parecer ser...», tanto de «ser». Este estar encubierto en el sentido de estar «desfigurado» es el más frecuente y más peligroso, porque aquí son especialmente tenaces las posibilidades de engaño y extravío. » [la cursiva es de Heidegger] M. Heidegger, El ser y el tiempo, ed. cit., pp. 46-47.

18 «Es la relación de quien ha luchado toda su vida por y contra la metafísica. Y esto quiere decir, en Heidegger: por y contra Hegel. Es la rebelión contra una tradición de la que se depende radicalmente, en pensamiento y lenguaje». F. Duque, «Con Hegel y Heidegger: Amenaza de la finitud», ed. cit., p. 14. Sin embargo, aunque Duque vea en ese «por y contra» una relación contradictoria de amor-odio, nosotros la entendemos, en cambio, en términos de resistencia. No se trataría entonces tanto de una «flagrante contradicción»-como si de una incoherencia se tratara-, sino, más bien, de la tensión inherente a toda resistencia auténtica. 
hacerlo. Así pues, el nivel de intervención, especialmente de los cursos sobre Hegel, refiere negativamente a aquellos comentarios que se quedan a mitad de camino, y al mismo tiempo señala positivamente y mediante un notorio gesto de admiración y valorización el pensamiento hegeliano. ${ }^{19}$ Es necesario entonces traspasar lo dicho por Hegel para hacer patente lo que, por abordarlo metafísicamente, su sistema debe dejar como lo no dicho. De esta manera, es importante percatarse de que la totalidad que se hace presente en el sistema de Hegel no es sino la totalidad de la metafísica, la totalidad de lo decible y pensable metafísicamente y que, no obstante, se encuentra atravesada por un impensado e indecible que ésta no logra apresar categorialmente - puesto que se trata de la propia resistencia a la captura categorial-, y al que debe apenas implicar dejándolo en la penumbra. ${ }^{20}$ En efecto, esta otra totalidad no puede sino ser inabarcable por la metafísica, al mismo tiempo que pone en cuestión su cierre y la concreción de lo absoluto.

Nos encontramos entonces con la paradoja de que el acabamiento y consumación de la metafísica deja como impensada la propia esencia de esta última, que debe entonces permanecer siempre abierta e imposibilitada de establecerse como la interpretación absoluta. La consumación de la metafísica se encuentra entonces muy lejos de un agotamiento del pensar. ${ }^{21}$ Por el contrario, el resto

19 Como ejemplo de esta admiración, valga una cita de Heidegger mencionada en el artículo ya mencionado de Félix Duque: «En efecto, en 1916, el fogoso y joven lector de Lutero, Kierkegaard y Dostoievski exige desde una «filosofía del espíritu viviente, del amor rico en obras, de la intimidad con Dios en la oración» una «controversia de principios con el sistema de cosmovisión histórica más poderoso tanto en abundancia como en profundidad, en riqueza vivencial y en formación conceptual» , o sea con Hegel». F. Duque, «Con Hegel y Heidegger: Amenaza de la finitud», ed. cit., p. 13. La cita de Heidegger corresponde a su escrito de habilitación Die Kategorien- und Bedeutungslehre des Duns Scotus. Tubinga, 1916, p. 241 (que corresponde a GA1).

20 Sobre la relación entre esta negatividad como indecible y el lenguaje entendido desde la metafísica cf. J. Derrida, «Cómo no hablar. Denegaciones», tr. P. Peñalver, Cómo no hablar y otros textos. Barcelona: Proyecto A, 1997; y G. Agamben, El lenguaje y la muerte. Un seminario sobre el lugar de la negatividad, tr. T. Segovia. Valencia: Pre-Textos, 2002.

21 «Con Hegel la filosofía, es decir, la filosofía antigua, en cierto sentido, ha sido pensada hasta el final. Estaba totalmente en lo cierto cuando expresa esta creencia. Pero había también la exigencia legítima de comenzar de nuevo, o sea, de comprender la finitud del sistema hegeliano y de ver que el mismo Hegel llegó al fin de la filosofía porque se movía en el círculo de los problemas filosóficos. Circular por este círculo le impedía volver a moverse en el centro del círculo y verlo de nuevo de forma radical. No es necesario salirse del círculo para buscar otro. Hegel vio todo lo que era posible ver. Pero la cuestión es si lo vio a partir del centro radical de la filosofía, si ha agotado todas las posibilidades de comenzar, hasta poder decir que ha llegado a su fin». (La cursiva es mía. HJC) M. Heidegger, Los problemas fundamentales de la fenomenología, ed. cit, pp. 338-339. 
que atraviesa la metafísica, manteniéndola inacabada, incluso -y especialmente- en su acabamiento, hace patente su precariedad y contingencia. Así pues, la esencia de la metafísica no puede llegar a su acabamiento desde un punto de vista metafísico o, dicho en otros términos, la metafísica se encuentra imposibilitada de un reconocimiento absoluto con su esencia, que debe persistir como lo siempre otro e inalcanzable para ella.

La esencia de la metafísica se sustrae entonces al influjo de esta última, aunque la filosofía de Hegel sea su mejor intento de reunirse consigo misma y de ese modo lograr una auténtica síntesis última. Por consiguiente, si la dialéctica hegeliana representa la consumación de la metafísica, la tensión de ésta con su esencia ya no puede ser remontada ni superada por una síntesis ulterior, puesto que el horizonte común que reúne a una con la otra es el de una radical diferenciación.

\section{Pensar la copertenencia}

Se discute con Hegel -y a través suyo con la historia de la metafísica- para su comprensión y no para su corrección, incluso si se busca señalar aquello que su filosofía presupone y deja como impensado y que, por esa razón, debe ser destacado para que la comprensión pueda ser efectiva. Por lo tanto, y frente a lo que pudiera parecer luego de una lectura apresurada del corpus heideggeriano, su crítica al sistema de Hegel no es sino una crítica interna que, ciertamente, pretende hacer visible el afuera que bajo el modo de los presupuestos impensados se hace presente al interior mismo de su filosofía. Pero impensados que son tales no por una desatención del autor, sino porque ejercen una resistencia radical a ser explicitados en el marco de la comprensión tradicional de la verdad.

En este sentido, podemos decir que Heidegger parte de una esencial coincidencia con Hegel: la filosofía de éste no es el capricho ni de un sujeto, ni de una época, sino la efectiva realización de una tendencia que ya se encontraba latente en el pensamiento presocrático. Esta coincidencia entre la manera en la que el propio Hegel presenta su filosofía y la consideración que Heidegger tiene de ella, tiene como punto destacado el hecho de que sea el propio Heidegger quien reconozca al sistema hegeliano como el fin de la filosofía. Sin embargo, y como mencionamos antes, aunque para ambos autores el sistema hegeliano constituya la consumación de la filosofía, no obstante para Heidegger ello no implica que el absoluto haya sido alcanzado. Por el contrario, la esencial inadecuación entre la metafísica y su esencia, que como dijimos impide una síntesis última, hace imposible la idea misma de un absoluto. La filosofía, entendida como sinónimo de metafísica, es entonces sólo un modo de darse - una tradición-de un pensar más abarcador que logra extenderse más allá de lo ente, pero que al mismo tiempo hace posible que este sea comprendido desde su origen. Este pensar tiene lugar en el espacio de copertenencia [Zusammengehörigkeit] 
que se abre entre la metafísica y su esencia, y que ampliando dicho espacio se propone abrir el fundamento abismal en cuya irrupción el sistema metafísico se resquebraja a partir de su esencial incompletitud.

Sintéticamente, podemos decir que la interpretación heideggeriana de Hegel se propone llegar hasta lo más profundo del pensamiento de este último con la intención de hacer patente el fundamento impensado sobre el que se sostiene su idea del Espíritu absoluto. Sin embargo, este fundamento impensado y abismal tiene como característica destacada el hecho de resistir a todo intento de captura por parte del concepto y, por lo tanto, saca a relucir que la totalidad propuesta por Hegel trae consigo una apertura originaria que la torna inacabada. Ese es el límite de la dialéctica, donde la contradicción entre la metafísica consumada y su condición de posibilidad no conducen a ninguna síntesis superadora, sino que permanecen en una tensión originaria y anterior, a la que Heidegger llamará «diferencia ontológica» [ontologische Differenz] -cuando se refiera a ella en el sentido de la distinción entre el ser y el ente-, «claro del ser» [Lichtung] -para señalar su carácter de condición de aparición y ocultamiento del darse-, «comarca» [Gegend] -indicándola como horizonte último-o «acontecimiento apropiante» [Ereignis] -cuando le interese destacarla como el origen de toda dación epocal del ser y toda interpretación. En cualquier caso, todos estos nombres- con los distintos sentidos por los cuales se refieren a lo que a nuestro modo de ver es un mismo fenómeno- presentan la particularidad de, por una parte, multiplicar el origen $y$, correlativamente, rehusarse a una síntesis última. ${ }^{22}$ Pese a su unidad lingüística, todos estos nombres se refieren a un fenómeno signado por su resistencia a la síntesis y la unidad y por la apertura de lo que Heidegger llama «copertenencia».

Esta expresión reaparece con insistencia una y otra vez en la obra de Heidegger, y ya sea que remita a la relación entre ser y ente, arte y verdad, aparición y ocultamiento, presencia y ausencia u hombre y ser, parece mentar la diferenciación originaria en tanto que inadecuación propia de la metafísica. En todos los casos, la copertenencia remite a lo que Heidegger caracteriza como la «convergencia en la divergencia» por la cual lo distinguido se reúne en torno a su imposibilidad de totalización. ${ }^{23}$

22 «Digamos: el Ereignis permite diversos «ensamblajes» entre el ser y el ente. Pero no se confunde con ninguno de sus momentos, ni siquiera con el «último» (en esto se diferencia de nuevo Heidegger de Hegel, para quien la última figura fenomenológica englobaba y resumía a todas las anteriores)». F. Duque, «Martin Heidegger: En los confines de la Metafísica», ed. cit., p. 27.

23 « [...] aquello que en el mismo respecto en el que concuerda también diverge cae en la discrepancia. Aquí la contraposición surge de la divergencia de lo que converge, de manera tal que en su separación alcanza precisamente su mayor copertenencia». M. Heidegger, Nietzsche I, tr. J. L. Vermal. Barcelona: Destino, 2000, p. 180. 
En este sentido, la copertenencia puede ser considerada como el reverso exacto de la síntesis dialéctica: si esta última totaliza a través del reconocimiento y la identificación especulatoria de los opuestos, para de esa manera llegar a una unidad superadora última, aquella avanza radicalizando la contradicción, de modo tal de hacer patente la esencial inadecuación de los miembros de la distinción. Una inadecuación que para ser tal implica la convergencia divergente, es decir, la persistencia en el reconocimiento de la diferencia - pólemos - y por ende la imposibilidad de toda síntesis que reúna a los opuestos superando su conflicto. Pero un reconocimiento que, en lugar de reducir a la mismidad, multiplica la diferencia. Convergiendo en la divergencia, la copertenencia profundiza las contradicciones y con ellas, simultáneamente, el enfrentamiento y reconocimiento.

Así pues, si la dialéctica hegeliana se proponía encontrar lo mismo en lo otro, la deconstrucción heideggeriana, en cambio, radicaliza lo otro en lo mismo. Su meta es mantener la diferencia y dejar así un resto para la resistencia. Una resistencia que hace posible el reconocimiento, sin el cual no es posible la resistencia. Y correlativamente, si el sistema de Hegel constituía la máxima ascensión hasta el despliegue total de la metafísica, la meditación de Heidegger, por el contrario, se propone el descenso hasta el fondo del abismo sobre el que aquel absoluto se sostendría. ${ }^{24}$ Un descenso que se propone reabrir una negatividad originaria anterior a la dialéctica y la metafísica, pero que constituye el origen de ambas. Una negatividad originaria de la que Heidegger se ocupará con detalle en su discurso « ¿Qué es metafísica?» y cuya relación deconstructiva respecto de la dialéctica hegeliana ha sido ya señalada por Agamben. ${ }^{25}$

Sin embargo, el trabajo del pensar heideggeriano se propone dar un paso más y, entre ascenso y descenso, reconocimiento y resistencia, apunta en última instancia a la radicalización del punto de fuga, la explicitación de un reconocimiento en la diferencia que mantiene siempre abierto y en movimiento al pensar.

24 «El pensar no supera la metafísica por el hecho de alzarse por encima de ella sobrepasándola y guardándola en algún lugar (clara alusión a la Aufhebung hegeliana), sino por el hecho de volver a descender a la proximidad de lo más próximo. El descenso, sobre todo cuando el hombre se ha estrellado ascendiendo hacia la subjetividad, es más difícil y peligroso que el ascenso. » (El interpolado es mío. HJC) M. Heidegger, «Carta sobre el humanismo», tr. H. Cortés y A. Leyte, en Hitos. ed. cit, p. 288.

25 Cf. M. Heidegger, «¿Qué es metafísica?», tr. H. Cortés y A. Leyte, Hitos. Madrid: Alianza, 2000, pp. 93-108; M. Heidegger, El ser y el tiempo, ed. cit., §58, sobre la invocación de la conciencia; y G. Agamben El lenguaje y la muerte. Un seminario sobre el lugar de la negatividad, ed. cit., especialmente pp. 89-101. 


\section{El EREIGNIS y LA DECONSTRUCCIÓN DEL ESPÍRITU}

Muy a grandes rasgos puede señalarse que los pensamientos de Hegel y Heidegger se mueven en dos direcciones claramente distintas: si el primero busca acompañar a la conciencia en el despliegue del absoluto; el segundo, en cambio, se dirige deconstructivamente hacia el sustrato último que hace posible dicho despliegue. Si el movimiento natural de la conciencia hegeliana es hacia aquello que Heidegger no dudará en llamar «consumación de la metafísica», éste último procurará hacer patente la condición de posibilidad de la metafísica misma, esto es, el horizonte o trasfondo -anterior a la distinción entre unidad y multiplicidad-sobre el que aparece toda presencia. En este sentido, y nuevamente de un modo muy general, podemos decir que la crítica heideggeriana se encuentra actuando ya sobre el primer eslabón de la Fenomenología del espíritu -la «certeza sensible»-, pero en una dirección inversa a la propuesta por Hegel en concordancia con la movilidad propia de la metafísica. Así pues, si la movilidad de ésta consiste en la resolución de las contradicciones, la Destruktion heideggeriana tendrá como operatoria el ahondamiento de las mismas.

Por consiguiente, si la movilidad propuesta por Hegel conduce desde la certeza sensible al entendimiento y de ahí a la razón como aquella forma que permite explicar la totalidad de las contradicciones, Heidegger se preguntará, en cambio, por aquello que antecede y se encuentra presupuesto en la certeza sensible misma. Esa condición de posibilidad será hallada en la comprensión del tiempo y el espacio. En efecto, en su curso sobre La fenomenología del espíritu de Hegel Heidegger sostiene que la determinación del «esto» peculiar a la certeza sensible, obedece a su caracterización espacio-temporal en términos de aquí y ahora. No obstante, el ahora es presentado allí como un compartimento vacío, determinado en el tiempo mismo y que por consiguiente no puede indicar con certeza al «esto» que permanece a lo largo del transcurso del tiempo. ${ }^{26}$ Así pues, ya desde este primer momento de la certeza sensible se encuentra actuando aquello que Heidegger no duda en denominar «comprensión vulgar del tiempo» y que se caracteriza por su comprensión como una sumatoria de ahoras, sin percatarse del trasfondo sobre el cual éstos transcurren.

Deconstruir la metafísica y con ello reinterpretar a Hegel equivale entonces a (re)poner a la comprensión vulgar del tiempo en el contexto de la temporalidad originaria, obturada por el primado de la presencia. No obstante, esto no significa en absoluto el desconocimiento, la enmienda o sencilla destrucción de

26 «El Aquí y el Ahora constituyen la estidad de un Esto [...] El Ahora, que es justamente este mediodía, ahora es mediodía. O conforme al Ahora, al Ahora que justamente era cuando Hegel interrogó a la certeza sensible por el Ahora, cuando escribió el texto: el Ahora es la noche. » M. Heidegger, La Fenomenología del Espíritu de Hegel, tr. M. E. Vázquez y K. Wrehde. Madrid: Alianza, 2008, p. 95. 
la interpretación metafísica del tiempo, sino que, muy por el contrario, implica su comprensión a partir de este otro horizonte anterior.

Si por un lado podemos decir que en la obra de Heidegger prima el intento de salirse de la metafísica entrando en su fundamento abisal obturado, al mismo tiempo debemos prestar suma atención al hecho, ya señalado, de que esta salida no es sino un retorno a la metafísica misma. El ser no sería entonces otra cosa que una inadecuación de lo ente consigo mismo, que hace posible volver renovadamente sobre él, de un modo análogo al retorno crítico al dato de la actitud natural peculiar a la reducción trascendental en la filosofía de Husserl. En este sentido, el proyecto heideggeriano de una deconstrucción de la metafísica puede ser leído como una hermenéutica de la metafísica misma en general y por lo tanto de Hegel en particular. La Destruktion llevada a cabo por Heidegger bien puede ser entendida entonces como una lectura en filigrana de la historia de la metafísica o directamente como la explicitación del horizonte hermenéutico dentro del cual es posible la comprensión cabal del sistema hegeliano.

Ahora bien, si como dijimos antes, los pensamientos de Hegel y Heidegger se dirigen en direcciones opuestas - uno intentando saldar las contradicciones y el otro profundizándolas-, la contracara del absoluto hegeliano estará dada por lo que Heidegger ha dado en llamar Ereignis y que en este punto puede ser comprendido como el reverso exacto del absoluto, esto es, por extraño que suene, como un absoluto entendido a partir de su posibilidad y, por ende, como el vacío que aparece como consecuencia de la puesta en suspenso o epojé del Espíritu.

Esta correspondencia entre el Espíritu hegeliano y el Ereignis se hace todavía más clara en la deconstrucción del concepto de espíritu que Heidegger emprende en la década de 1940, no casualmente - por lo que respecta a la relación planteada con Hegel- a partir de un fragmento de Hölderlin: «Entre nosotros, todo se concentra sobre lo espiritual, nos hemos vuelto pobres para llegar a ser ricos»». ${ }^{27}$

El análisis de dicho fragmento es presentado por Heidegger en 1945, en un discurso que lleva el nombre «La pobreza» [Die Armut] y que tiene como objetivo la deconstrucción de la comprensión tradicional del espíritu a partir de la verdad como presencia.

Enfrentado al Espíritu absoluto entendido como presencia plena, el espíritu es presentado por Heidegger en términos de pobreza, carencia y menesterosidad. Frente al Espíritu que consuma la metafísica, se encuentra este otro espíritu de

27 Citado en M. Heidegger, La pobreza, trad. I. Agoff. Buenos Aires: Amorrortu, 2006, p. 93. Sobre esta deconstrucción heideggeriana del espíritu Cf. J. Derrida, Del espíritu, tr. M. Arranz. Valencia: Pre-textos, 1989. 
la carencia absoluta, es decir, de la apertura absoluta dentro de la cual pueden darse los entes. En este sentido, el espíritu entendido heideggerianamente como pobreza, carencia y apertura, remite al Ereignis y al claro del ser [Lichtung] entendidos como aquel horizonte o trasfondo último que actúa como condición de posibilidad de toda dación y que no obstante resiste cualquier presentación. El espíritu así entendido es, dicho nietzscheanamente, el espacio abierto que se ha hecho patente con la muerte de Dios y los valores absolutos, en el cual es necesario sumergirse para dejar imperar lo ente. ${ }^{28}$ Así pues, para llegar a la riqueza del absoluto metafísico de Hegel, es necesario primero haber descendido a la pobreza del Ereignis.

\section{CONCLUSIÓN}

A lo largo del presente trabajo hemos procurado abordar las ontologías de Hegel y Heidegger a partir de lo que podríamos denominar su «complementariedad deconstructiva». Ello quiere decir que la Destruktion heideggeriana de la metafísica, así también como su lectura de la Fenomenología del Espíritu de Hegel, no son otra cosa que la explicitación del marco dentro del cual ambas pueden ser al mismo tiempo puestas en cuestión y comprendidas desde su fundamento. Se trata entonces de comprender críticamente la tradición de la que formamos parte y a través de la cual nos enfrentamos con lo dado. Ahora bien, ese marco que hace posible la comprensión crítica de la metafísica no es otro que el ser mismo, el cual es necesario arrancar del olvido al que ha sido confinado por una tradición de pensamiento que tiende a superar las resistencias, para hacerlo patente en tanto que aquello que se oculta en la explicitación del ente o, dicho en otros términos, como aquello que resiste a ser desocultado. Como fruto de esta elucidación de la resistencia radical será posible, en primer lugar, la comprensión de la metafísica a partir de su fundamento, pero también una resistencia en términos políticos ante la dominación técnico-científica de la naturaleza arraigada en la metafísica, y ante cuya esencia, sostiene Heidegger, «la mediación dialéctica pasa de largo».29 Frente a ese «pasar de largo» de la dialéctica, será necesario entonces ahondar en ese espacio (no) más allá de la metafísica, donde la esencia de la técnica aparece como la Gestell [estructura de emplazamiento] al mismo tiempo que destella el Ereignis.

28 Este descenso en lo abierto debe ser pensado a partir de la «serenidad» [Gelassenheit] Cf. M. Heidegger, Serenidad, tr. Y. Zimmermann. Barcelona: Del serbal, 1994.

29 M. Heidegger, Denkerfahrungen. Frankfurt am Main: Klostermann, p. 152 (GA 13) Cf. también D. O. Dahlstrom, loc. cit., p. 76: «Thus, while Hegel's notion of absolute subjectivity represents the beginning of the completion of metaphysics and Nietzsche's will to power its penultimate stage, «technology» constitutes its utter completion». 
Tal vez sea en este segundo punto donde deban rastrearse las razones que han motivado la resistencia contemporánea al pensamiento de Hegel a lo largo del siglo XX, por autores que han atendido muy especialmente a la cuestión ineludible de la alteridad y la diferencia. Es en este contexto que debe ser enmarcada la posibilidad de un reconocimiento de la diferencia, que, frente a los intentos de síntesis y conclusión, oponga la multiplicación y diseminación como condiciones de una convergencia en la divergencia. Lo que equivale a la apertura de un reconocimiento de la alteridad, mucho más difícil, claro está, que el reconocimiento de lo idéntico, pero fundamental si se trata de comprendernos a nosotros mismos. Un reconocimiento de la alteridad que no puede tener otro sostén que la escucha al otro, su resistencia a la adecuación, pero por sobre todo su capacidad radical de ponernos en cuestión.

Hernán JaVIER CANDILORo pertenece al Consejo Nacional de Investigaciones Científicas y Técnicas (CONICET) y Universidad de Buenos Aires (UBA).

Linea de investigación

El Selbst en la filosofía de Heidegger y sus derivas contemporáneas. Una crítica a la subjetividad moderna.

Publicaciones recientes

«Pobreza, vida y animalidad en el pensamiento de Heidegger», Areté. Revista de Filosofía, Volumen XXIV, $\mathrm{N}^{\circ} 2$ (2012), pp. 263-287.

«Reseña de El pensamiento político posfundacional de Oliver Marchart», Anuario Filosófico de la Universidad de Navarra, 1 (2012), pp. 191-194.

Dirección electrónica: hernancandiloro@hotmail.com 